\title{
Socio-demographic Predictors of Knowledge of Ebola Virus Disease among Future Healthcare Professionals
}

\author{
Muhammad Shahid Iqbal ${ }^{1, *}$, Muhammad Zahid Iqbal ${ }^{2}$, Salah-Ud-Din Khan ${ }^{3}$, Javed Khan ${ }^{4}$ \\ 'Department of Clinical Pharmacy, College of Pharmacy, Prince Sattam bin Abdulaziz University, Al-kharj, SAUDI ARABIA \\ 2Department of Clinical Pharmacy and Pharmacy Practice, Faculty of Pharmacy, AIMST University, 08100, Bedong, Kedah Darul Aman, MALAYSIA. \\ 3Department of Biochemistry, College of Medicine, Imam Mohammad Ibn Saud Islamic University, Riyadh, SAUDI ARABIA. \\ ${ }^{4}$ Department of Public Health, College of Health Sciences, Saudi Electronic University, 11673, Riyadh, SAUDI ARABIA.
}

\begin{abstract}
Objectives: The current study evaluated the knowledge and its predictors regarding the Ebola Virus Disease (EVD) among future healthcare professionals in a university in Malaysia. Methods: A cross-sectional study approach was utilized to recruit the study participants from three different healthcare faculties of a university. A validated research tool with a data collection form was used to obtain data by convenience sampling method. The healthcare faculties involved in the present research were pharmacy, dentistry, and medical. The Statistical Package for Social Science (SPSS) version 24.0 was used to analyze the data. Results: In the current study, a total of 273 participants were recruited. The majority of the study participants had an average and inadequate knowledge about EVD. The male participants had better adequate knowledge than females. Both univariate and multivariate logistic regression models were applied to determine the predictors of knowledge about EVD among the
\end{abstract}

study participants. Statistically, a significant level was taken at $p<0.05$. Conclusion: Gender and healthcare professionals in the family were observed as the pure predictors of knowledge regarding EVD among the study participants.

Key words: Knowledge, EVD, Predictors, Future healthcare professionals, Students

\section{Correspondence}

Dr. Muhammad Shahid lqbal

Department of Clinical Pharmacy, College of Pharmacy, Prince Sattam bin Abdulaziz University, Al-kharj-11942, SAUDI ARABIA.

Email: m.javed@psau.edu.sa

DOI: 10.5530/jyp.2021.13.31

\section{INTRODUCTION}

Ebola Virus Disease (EVD) is possibly a dangerous disease caused by five different ebolavirus species. Sometimes earlier, this EVD was also known as Ebola hemorrhagic fever that had a dangerous outbreak in West Africa. ${ }^{1-3}$ EVD often characterized by a deadly internal hemorrhage with high mortality rates. In various African countries, its life-threatening effects resulted in more than $90 \%$ causalities among the total infected patients. ${ }^{3-5}$ Due to limited treatment choices and vaccines, most of the communities faced a high fatality rate and numerous comorbidities at a larger scale., ${ }^{5,6}$ The major and life-threatening indications of EVD included high and continuous fever, multiple organ failure, febrile hemorrhagic abnormalities, bloody vomiting, extreme fatigue, headache clusters, massive internal bleeding, and intensive diarrhea. ${ }^{7-9}$

The Ebola virus is a negative-strand RNA virus that causes an acute serious illness which is often fatal if untreated. Ebola virus belongs to the Filoviridae family and it comprises of 6 distinct species and out of these 6 species, 4 are fatal to humans. They are Bundibugyo ebolavirus (BEV), Zaire ebolavirus (ZEV), Sudan ebolavirus (SEV), and Taï Forest ebolavirus (TFV). ${ }^{1-4}$ EVD first appeared in 1976 in 2 simultaneous outbreaks, one in Yambuku, Democratic Republic of Congo and the other in Nzara, Sudan., ${ }^{3,10-12}$ The latter occurred in a village near the Ebola River, from which the disease took its name. In the first quarter of 1995, another outbreak of EVD occurred in Zaire, Africa which was traced to a forest worker who had been believed to be infected on December 1994. ${ }^{6-9}$ People who had infected with the virus developed symptoms of hemorrhagic fever including muscle aches. ${ }^{9-12}$ Since it first outbreaks in 1976, there has been around a million of suspected and laboratory- confirmed cases of EVD reported in Africa, making it persistently exposed to the EVD. ${ }^{13-17}$

Besides, self-defense and self-care are of utmost importance for selfsafety and overall national safety. ${ }^{18,19}$ Although in Malaysia, EVD is not yet prevalent but due to its contagious nature, it can be a big future threat that may turn into a pandemic or an epidemic threat for the country. The govt in Malaysia had also paid special attention and designed persuasive prevention strategies to deal with any emergency to combat with EVD epidemic. This study aimed to evaluate the socio-demographic predictors of knowledge towards EVD among future healthcare professionals in Malaysia and to determine how these predictors affect EVD knowledge among them.

\section{MATERIALS AND METHODS}

This study was performed by a convenient sampling technique. The study participants were recruited from three different healthcare faculties i.e. pharmacy, dentistry, and medicine. The study was started after receiving verbal or written consent. Inclusion criteria included those participants who signed the consent and volunteer to participate. The consent forms for participation in the study were only given to those who were volunteer to participate. Those study participants who refused to participate in the current study were not forced to take part. All of the information was strictly confidential, protected, and was used for the research only.

This study used a validated research instrument to evaluate the knowledge and effect of socio-demographic predictors of knowledge regarding EVD among future healthcare professionals. The research instrument

This is an open access article distributed under the terms of the Creative Commons Attribution-NonCommercial-ShareAlike 4.0 License, which allows others to remix, tweak, and build upon the work non-commercially, as long as the author is credited and the new creations are licensed under the identical terms. 
was prepared (preliminary) after an extensive literature review and with the help of content experts in the relevant field. Later, the final version of the study tool was obtained after doing the suggested modifications. The final version was further validated and piloted to be used for data collection.

The study participants had to read carefully and choose one best answer according to their knowledge from given choices of each statement. All of the responses were recorded as correct and incorrect answers. Grading of the scores was done similar to some previous studies where a score of 1 was allotted to each correct answer and nothing for an incorrect answer. ${ }^{19}$ According to the set criteria, correct answers $0-6(<60 \%)$ were considered as inadequate knowledge, and correct answers 7-10 (>60\%) were taken as adequate knowledge.

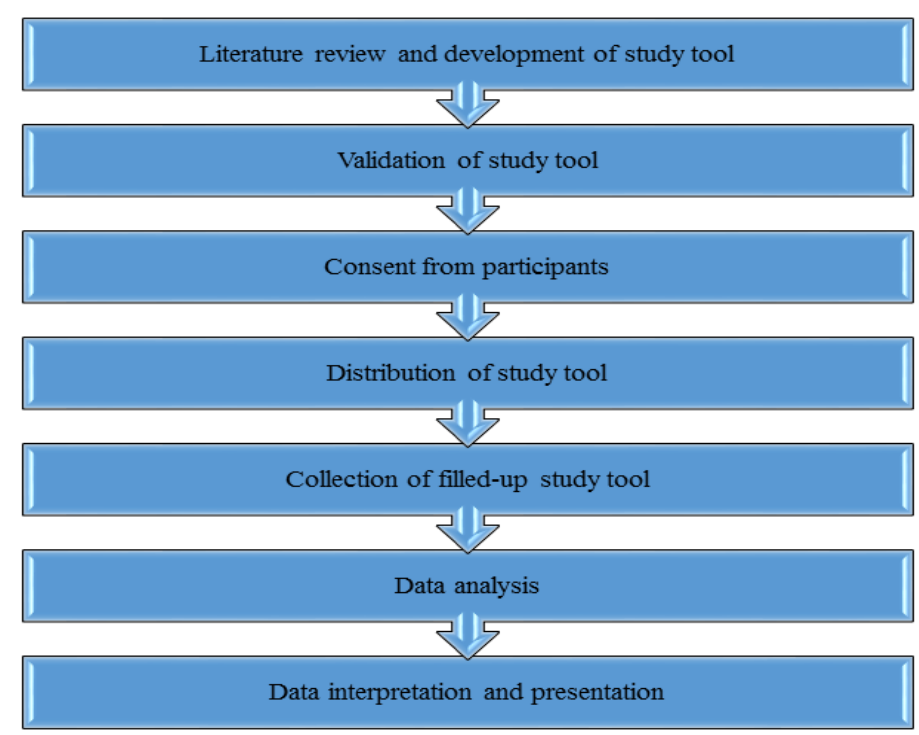

Figure 1: Flow chart of study.

The study flow chart is presented in Figure 1, as follows

\section{Statistical Analyses}

During the analysis of the data, frequencies and percentages were determined for the categorical variables, and means and standard deviations were obtained for the continuous variables. Pearson Chisquare test was applied to observe the significant differences between the studied variables. A $p$-value of $<0.05$ was considered statistically significant. The socio-demographic predictors were determined using a multivariate logistic regression with the Wald statistical criteria. Those categorical variables that were statistically significant $(p$-value $<0.05)$ in the univariate analysis were further analyzed using the multivariate analysis to determine pure predictors of the knowledge regarding EVD among future healthcare professionals. The fit of the model was assessed by Hosmer Lemeshow and the overall classification percentage.

\section{RESULTS}

The demographic details of the study participants are presented in Table 1 . There was a total of 273 study participants were involved and around $103(37.7 \%)$ were male students whereas $170(62.3 \%)$ were female students. The participation percentage among the three studied healthcare faculties was as follows, pharmacy 99 (36.3\%), dentistry 90 (33.0\%), and medicine 84 (30.8\%).

Table 2 indicates the knowledge score (N\%) from the study participants as inadequate and adequate knowledge. A total of 10 statements (questions) were asked from the study participants about EVD regarding its origin, types, precautions, incubation periods, and treatment, etc.

Table 3 illustrates the predictors of knowledge of EVD among future healthcare professionals. Findings from univariate and multivariate regression model analysis are presented. A total of four predictors were observed as statistically significant $(p<0.05)$ in univariate analysis. For multivariate logistic regression analysis, only two predictors were found to be statistically significant $(p<0.05)$.

\section{DISCUSSION}

In our study, the results showed that the majority of future healthcare professionals had appropriate knowledge about EVD. In the faculty of pharmacy, around 61 (61.6\%) had inadequate knowledge and 38 (38.4\%) had adequate knowledge about EVD. Among faculty of dentistry, around $64(71.1 \%)$ had inadequate and only $26(28.9 \%)$ had adequate knowledge about EVD. For medicine faculty participants, a total of $61(72.6 \%)$ had inadequate EVD knowledge and just 23 (27.4\%) had adequate knowledge. In comparison between the three healthcare faculty students, pharmacy students had the best adequate knowledge than both

Table 1: Demographic characteristics of study participants $(n=273)$.

\begin{tabular}{lc}
\hline Variable & $\mathrm{N}(\%)$ \\
\hline Faculty & $99(36.3)$ \\
Pharmacy & $90(33.0)$ \\
Dentistry & $84(30.7)$ \\
Medicine & \\
Year of education & $135(49.5)$ \\
Pre-final & $138(50.5)$ \\
Final & \\
Age groups & $207(97.8)$ \\
$<25$ years & $66(1.5)$ \\
$>25$ years & \\
Gender & $103(37.7)$ \\
Male & $170(62.3)$ \\
Female & \\
Race & $108(28.8)$ \\
Malay & $165(71.2)$ \\
Chinese & $23(8.4)$ \\
Indian & $164(60.1)$ \\
Educational background & $86(31.5)$ \\
STPM & \\
Diploma & $13(4.8)$ \\
Foundation & \\
Residence & $14(5.1)$ \\
Hosteller & \\
Non- Hosteller & \\
\hline Healthcare professionals in family & \\
\hline
\end{tabular}

Footnote: Categorical data type in the form of $\mathrm{N}$ (\%) with the study demographics, type of statistical analysis used was frequency and percentages 
of the studied faculties. The lowest knowledge about EVD was observed among medical students. In contrast with our study findings, another earlier study conducted among medical clinicians showed that only 93\% of them were familiar with the EVD. ${ }^{9}$ Our study results are better than them as in our study among all three faculty students showed around $40 \%$ of the knowledge and awareness about EVD.

Malaysia is a country that is famous for its tourist attractions where daily plentiful travelers and visitors visit the country so there are high possibilities for the outbreak of contagious diseases like EVD. The current study was conducted among healthcare students which are future healthcare professionals, and they could be facing such issues and dealing with such diseases after their graduation. And in the future, inadequate or inappropriate knowledge about EVD may lead to wrong diagnosis and inappropriate treatments that might affect the patients. ${ }^{9,20}$ Regarding self-protectiveness among individuals, the use of facemasks, proper hygiene, and wearing gloves are believed to be essential measures in handling and treating patients infected with EVD. The interesting finding of the current study was that those participants who were familiar with EVD and had adequate knowledge of the disease were very

Table 2: Knowledge of study participants.

\begin{tabular}{|c|c|c|}
\hline \multirow[t]{2}{*}{ Variables } & \multicolumn{2}{|c|}{ Knowledge of MHCs (N \%) } \\
\hline & Inadequate & Adequate \\
\hline \multicolumn{3}{|l|}{ Faculty } \\
\hline Pharmacy & $61(61.6)$ & $38(38.4)$ \\
\hline Dentistry & $64(71.1)$ & $26(28.9)$ \\
\hline Medicine & $61(72.6)$ & $23(27.4)$ \\
\hline \multicolumn{3}{|l|}{ Year of education } \\
\hline Pre-final & $41(30.4)$ & $94(69.6)$ \\
\hline Final & $46(33.3)$ & $92(66.7)$ \\
\hline \multicolumn{3}{|l|}{ Age groups } \\
\hline$<25$ years & $151(72.9)$ & $56(27.1)$ \\
\hline$>25$ years & $34(51.5)$ & $32(48.5)$ \\
\hline \multicolumn{3}{|l|}{ Gender } \\
\hline Male & $46(44.7)$ & $57(55.3)$ \\
\hline Female & $120(70.6)$ & $50(29.4)$ \\
\hline \multicolumn{3}{|l|}{ Race } \\
\hline Malay & $12(52.2)$ & $11(47.8)$ \\
\hline Chinese & $113(68.9)$ & $51(31.1)$ \\
\hline Indian & $61(70.9)$ & $25(29.1)$ \\
\hline \multicolumn{3}{|l|}{ Educational background } \\
\hline STPM & $8(57.1)$ & $6(42.6)$ \\
\hline Diploma & $12(66.7)$ & $6(33.3)$ \\
\hline Foundation & $157(68.9)$ & $71(31.1)$ \\
\hline Others & $9(69.2)$ & $4(30.8)$ \\
\hline \multicolumn{3}{|l|}{ Residence } \\
\hline Hosteller & $137(68.5)$ & $63(31.5)$ \\
\hline Non- Hosteller & $49(67.1)$ & $24(32.9)$ \\
\hline \multicolumn{3}{|c|}{ Healthcare professionals in family } \\
\hline Yes & $75(69.4)$ & $33(30.6)$ \\
\hline No & 154 (93.3) & $11(6.7)$ \\
\hline
\end{tabular}

Footnote: Categorical data type in the form adequate and inadequate knowledge of respondents. Statistical analysis used was Fisher's Exact /Chi-Square tests
Table 3: Predictors of knowledge about EVD.

\begin{tabular}{|c|c|c|c|c|}
\hline \multirow[t]{2}{*}{ Variables } & \multicolumn{2}{|c|}{ Univariate analysis } & \multicolumn{2}{|c|}{ Multivariate analysis } \\
\hline & $\begin{array}{l}\operatorname{COR}(95 \% \\
\text { Cl) }\end{array}$ & $P$-value & $\begin{array}{l}\text { AOR }(95 \% \\
\text { Cl) }\end{array}$ & $P$-value \\
\hline \multicolumn{5}{|l|}{ Faculty } \\
\hline Pharmacy & 1 & & & \\
\hline Dentistry & $\begin{array}{c}0.587 \\
(0.12-0.99)\end{array}$ & 0.623 & & \\
\hline Medicine & $\begin{array}{c}1.092 \\
(0.48-2.53)\end{array}$ & 0.721 & & \\
\hline \multicolumn{5}{|l|}{ Year of education } \\
\hline Pre-final & 1 & & 1 & \\
\hline Final & $\begin{array}{l}0.458(0.31- \\
0.77)\end{array}$ & $0.037^{*}$ & $\begin{array}{c}0.305 \\
(0.20-0.63)\end{array}$ & 0.261 \\
\hline \multicolumn{5}{|l|}{ Age groups } \\
\hline$<25$ years & 1 & & & \\
\hline$>25$ years & $\begin{array}{c}1.326 \\
(0.83-1.72)\end{array}$ & 0.152 & & \\
\hline \multicolumn{5}{|l|}{ Gender } \\
\hline Male & 1 & & 1 & \\
\hline Female & $\begin{array}{c}1.172 \\
(0.37-2.55)\end{array}$ & $0.017^{*}$ & $\begin{array}{c}0.878 \\
(0.52-0.92)\end{array}$ & $0.048^{*}$ \\
\hline \multicolumn{5}{|l|}{ Race } \\
\hline Malay & 1 & & & \\
\hline Chinese & $\begin{array}{c}1.734 \\
(0.58-2.25)\end{array}$ & 0.131 & & \\
\hline Indian & $\begin{array}{c}0.892 \\
(0.44-1.56)\end{array}$ & 0.532 & & \\
\hline \multicolumn{5}{|l|}{$\begin{array}{l}\text { Educational } \\
\text { background }\end{array}$} \\
\hline STPM & 1 & & & \\
\hline Diploma & $\begin{array}{c}0.920 \\
(0.31-2.03)\end{array}$ & 0.092 & & \\
\hline Foundation & $\begin{array}{c}0.754 \\
(0.21-1.59)\end{array}$ & 0.121 & & \\
\hline Others & $\begin{array}{c}1.003 \\
(0.77-2.78)\end{array}$ & 0.089 & & \\
\hline \multicolumn{5}{|l|}{ Residence } \\
\hline Hosteller & 1 & & 1 & \\
\hline Non- Hosteller & $\begin{array}{c}2.808 \\
(0.64-3.26)\end{array}$ & $0.039^{*}$ & $\begin{array}{c}1.324 \\
(1.43-1.34)\end{array}$ & 0.223 \\
\hline \multicolumn{5}{|c|}{$\begin{array}{l}\text { Healthcare } \\
\text { professionals in family }\end{array}$} \\
\hline Yes & 1 & & 1 & \\
\hline No & $\begin{array}{c}0.132 \\
(0.09-1.08)\end{array}$ & $0.018^{\star}$ & $\begin{array}{c}1.003 \\
(0.23-2.36)\end{array}$ & $0.047^{\star}$ \\
\hline
\end{tabular}

Footnote: Type of data was categorical data. Statistical analysis used was Logistics Regression with $1=$ Referent; $\mathrm{SD}=$ Standard Deviation; $\mathrm{COD}=$ Crude Odds Ratio; $\mathrm{AOD}=$ Adjusted Odds Ratio; $\mathrm{CI}=$ Confidence Interval; ${ }^{*}$ Statistically Significant $(<0.05)$ 
Iqbal, et al:: Predictors of Knowledge about EVD among FHCPs

informed about all of this information and precautions. These results were similar to another study where the participants were also very well informed about such measures. ${ }^{21}$

In univariate analysis, our findings indicated that four socio-demographic predictors e.g. year of education, gender, residence, and healthcare professionals in family showed statistically significant differences $(p<0.05)$ among them. In the 'year of education' predictor, COR 0.458 with $p=0.037$ was observed. In the second predictor 'gender' (COR $1.172 ; p=0.017$ ) was noted where $35.9 \%$ of male participants and $29.4 \%$ of females had adequate knowledge about EVD. These findings indicated that more male students had adequate knowledge than female students. Moreover, other studies reported opposite results that female students had more adequate knowledge than males. ${ }^{21,22}$ In our study, students from medical faculty had more inadequate knowledge about EVD than the rest. In the third variable, 'residence' the non-hostellers had better knowledge than the hostlers with (COR 2.808; $p=0.039$ ). In the last predictor determined by the univariate analysis, 'parents' education' was also found that those students who had a healthcare professional in their family scored better knowledge about EVD than the other group (COR $0.132 ; p=0.018)$.

By using multiple logistic regression, pure determinants of adequate knowledge about EVD were investigated by controlling and adjusting all confounders through the multivariate logistic model. According to the results obtained by the logistic regression analysis, two pure predictors were inferred e.g. gender and healthcare professionals in family. Regarding 'gender', after adjusting the outliers or the rest of the studied demographic variables, adjusted odds of 0.878 with a $p$-value of 0.048 were obtained i.e. (AOR $0.878 ; p=0.048$ ). For the second sociodemographic predictor of 'healthcare professionals in family' pure odds of 1.003 with a $p$-value of 0.047 were obtained i.e. (AOR $1.003 ; p=0.047$ ). These findings show that with any change in gender, the knowledge will be changed to 0.878 . On the other hand, any change in having healthcare professionals in the family will increase knowledge of 1.003. Undeniably, the healthcare literacy is always high in those families which had healthcare professionals. , $^{172,23}$

\section{CONCLUSION}

This study evidenced that gender, and healthcare professionals in the family were the pure predictors of knowledge regarding EVD among future healthcare professionals. There was no previous study conducted among future healthcare professionals in the studied region of Malaysia about the knowledge and awareness regarding EVD.

\section{ACKNOWLEDGEMENT}

The authors would like to thank the Deanship of Scientific Research at Prince Sattam bin Abdulaziz University, Alkharj, Saudi Arabia, for the support of this publication.

\section{CONFLICT OF INTEREST}

The authors declare no conflict of interest.

\section{ABBREVIATIONS}

EVD: Ebola Virus Disease; SPSS: Statistical Package for Social Sciences; SD: Standard Deviation; COD: Crude Odds Ratio; AOD: Adjusted Odds Ratio; CI: Confidence Interval.

\section{REFERENCES}

1. Baseler L, Chertow DS, Johnson KM, Feldmann H, Morens DM. The Pathogenesis of Ebola Virus Disease. Annu Rev Pathol. 2017;12:387-418.

2. Broadhurst MJ, Brooks TJ, Pollock NR. Diagnosis of Ebola Virus Disease: Past, Present and Future. Clin Microbiol Rev. 2016;29(4):773-93.

3. Murray MJ. Ebola Virus Disease: A Review of Its Past and Present. Anesth Analg. 2015;121(3):798-809.

4. Arima $Y$, Shimada T. Epidemiological situation of Ebola virus disease in West Africa. Uirusu. 2015;65(1):47-54.

5. Abebe TB, Bhagavathula AS, Tefera YG, Ahmad A, Khan MU, Belachew SA, et al. Healthcare Professionals' Awareness, Knowledge, Attitudes, Perceptions and Beliefs about Ebola at Gondar University Hospital, Northwest Ethiopia: A Crosssectional Study. J Public Health Afr. 2016;7(2):570.

6. Iliyasu G, Ogoina D, Otu AA, Dayyab FM, Ebenso B, Otokpa D, et al. A Multi-Site Knowledge Attitude and Practice Survey of Ebola Virus Disease in Nigeria. PLoS One. 2015;10(8):e0135955.

7. Paweska JT, Moolla N, Storm N, Msimang V, Conteh O, Weyer J, et al. Evaluation of Diagnostic Performance of Three Indirect Enzyme-linked Immunosorbent Assays for the Detection of IgG Antibodies to Ebola Virus in Human Sera. Viruses. 2019;11(8):678.

8. Shears P, O'Dempsey TJ. Ebola virus disease in Africa: Epidemiology and nosocomial transmission. J Hosp Infect. 2015;90(1):1-9.

9. Ajayi NA, Ojide CK, Ajayi IA, Ukwaja KN. Evaluation of clinicians' knowledge of and attitudes to Ebola virus disease in Ebonyi State, Nigeria. J Virus Erad. 2019:5(3):145-51.

10. Adongo PB, Tabong PT, Asampong E, Ansong J, Robalo M, Adanu RM. Beyond Knowledge and Awareness: Addressing Misconceptions in Ghana's Preparation towards an Outbreak of Ebola Virus Disease. PLoS One. 2016;11(2):e0149627.

11. Nicastri E, Kobinger G, Vairo F, Montaldo C, Mboera LEG, Ansunama R, et al. Ebola Virus Disease: Epidemiology, Clinical Features, Management and Prevention. Infect Dis Clin North Am. 2019;33(4):953-76.

12. Gupta N, Mehta N, Gupta P, Arora V, Setia P. Knowledge regarding Ebola Hemorrhagic Fever among private dental practitioners in Tricity, India: A crosssectional questionnaire study. Niger Med J. 2015;56(2):138-42.

13. Andreas A, Egom CBA, Kruzliak P, Egom EE. Is there a way out for the 2014 Ebola outbreak in Western Africa?. Asian Pac J Trop Med. 2015;8(10):773-8.

14. Olowookere SA, Abioye-Kuteyi EA, Adepoju OK, Esan OT, AdeoluTM, AdeoyeTK, et al. Knowledge, Attitude and Practice of Health Workers in a Tertiary Hospital in Ile-Ife, Nigeria, towards Ebola Viral Disease. J Trop Med. 2015;2015(1):431317.

15. Wilken JA, Pordell P, Goode B, Jarteh R, Miller Z, Saygar BG, et al. Knowledge, Attitudes, and Practices among Members of Households Actively Monitored or Quarantined to Prevent Transmission of Ebola Virus Disease - Margibi County, Liberia: February-March 2015. Prehosp Disaster Med. 2017;32(6):673-8.

16. Oladimeji AM, Gidado S, Nguku P, Nwangwu IG, Patil ND, Oladosu F, et al. Ebola virus disease - gaps in knowledge and practice among healthcare workers in Lagos, August 2014. Trop Med Int Health. 2015;20(9):1162-70.

17. Idris BJ, Inem V, Balogun M. Comparing the knowledge, attitude and practices of health care workers in public and private primary care facilities in Lagos State on Ebola virus disease. Pan Afr Med J. 2015;22(Suppl 1):19.

18. Almutairi KM, Alodhayani AA, Moussa M, Aboshaiqah AE, Tumala RB, Vinluan JM. Ebola outbreak preparedness and preventive measures among healthcare providers in Saudi Arabia. J Infect Dev Ctries. 2016;10(8):829-36.

19. Ilesanmi O, Alele FO. Knowledge, Attitude and Perception of Ebola Virus Disease among Secondary School Students in Ondo State, Nigeria, October, 2014. PLoS Curr. 2016;8(1):1-9

20. Chilton JM, McNeill C, Alfred D. Survey of Nursing Students' Self-Reported Knowledge of Ebola Virus Disease, Willingness to Treat and Perceptions of their Duty to Treat. J Prof Nurs. 2016;32(6):487-93.

21. Hisam A, Rana MN, Mahmood-Ur-Rahman. Knowledge and attitude regarding Ebola virus disease among medical students of Rawalpindi: A preventable threat not yet confronted. Pak J Med Sci. 2016;32(4):1015-9.

22. Shook E, Curtis A, Curtis J, Gibson G, Horst VA, Little V, et al. Assessing the Geographic Context of Risk Perception and Behavioral Response to Potential Ebola Exposure. Int J Environ Res Public Health. 2019;16(5):831.

23. Etokidem AJ, Ago BU, Mgbekem M, Etim A, Usoroh E, Isika A. Ebola virus disease: Assessment of knowledge, attitude and practice of nursing students of a Nigerian University. Afr Health Sci. 2018:18(1):55-65. 